\title{
Attempted use of haloperidol in the treatment of L-dopa induced dyskinesias ${ }^{1}$
}

\author{
HAROLD L. KLAWANS, JR. ${ }^{2}$ AND WILLIAM J. WEINER \\ From the Department of Neurological Sciences and Department of Medicine \\ (Section of Pharmacogenetics), Rush Medical College, Chicago, Illinois, U.S.A.
}

SYNOPSIS Haloperidol was used in 12 patients in an attempt to improve L-dopa induced dyskinesias. In eight patients any improvement in dyskinesias was associated with increased Parkinsonism. In four patients the dyskinesias initially improved without clinical deterioration. Within several weeks, however, the disability due to Parkinsonism increased in these four patients as well. These observations suggest that long term haloperidol does not effectively decrease L-dopa induced dyskinesias without worsening Parkinsonism.

One of the most troublesome and frequent sideeffects of long-term L-dopa therapy of Parkinsonism is the occurrence of abnormal involuntary movements, or dyskinesias, first reported by Cotzias et al. (1967) in their initial report on the efficacy of long-term high dosage DL- and L-dopa in Parkinsonism. The incidence reported during chronic therapy ranges from a low of $39 \%$ (Godwin-Austen et al., 1969) to as high as $80 \%$ (Barbeau, 1969).

The variety of movement disorders induced by L-dopa in this population is quite diverse. Lingual-facial-buccal movements, such as grimacing, gnawing, yawning, and choreoathetoid movements of the tongue appear to be the most frequent movements observed. Jerking and myoclonic movements of various neck and facial muscles can occur. Choreoathetoid movements of the extremities are also common (Cotzias et al., 1969; Klawans and Garvin, 1969; Yahr et al., 1969; Barbeau et al., 1970). It is noteworthy that only the diverse phenomena described 40 to 50 years ago during the acute phase of von Economo's encephalitis or more recently in relation to the tardive dyskinesias of neuroleptic therapy include a comparable range of abnormal movements.

While the diversity of these movements is

1 This work was supported by a grant from the United Parkinsonism Foundation, Chicago, Illinois.

2 Present address: Division of Neurology, Michael Reese Medical Center, Chicago, Ill. 60616, U.S.A. remarkable, it is their frequency and subsequent effect on the long-term efficacy of L-dopa that is most significant. Once these movements appear, they tend to persist unless some therapeutic measure is taken, most commonly decrease of the daily dosage of L-dopa, which all observers agree will decrease the severity of L-dopa induced dyskinesias. Unfortunately, the beneficial effects of L-dopa on the Parkinsonian symptoms of these same patients is usually diminished at the same time, so L-dopa induced dyskinesias often limit both the dosage of L-dopa a patient can tolerate and the clinical efficacy of L-dopa. The need for other ways to decrease L-dopa induced dyskinesias has led to various therapeutic attempts including pyridoxine (Jameson, 1970), phenothiazine (Barbeau, 1969), and haloperidol (Postma, 1972). Because of the possibility that these movements may be related to denervation hypersensitivity of dopamine facilitated striatal neurones (Klawans, 1973) and because such neurones may be more easily blocked by neuroleptic agents than other striatal neurones (York, 1970), we undertook a systematic evaluation of the use of haloperidol in the treatment of L-dopa induced dyskinesias.

\section{METHODS AND RESULTS}

Twelve patients with Parkinsonism who had been on L-dopa for at least six months were included in this study. The patients ranged in age from 43 to 71 with 
TABLE 1

INITIAL EVALUATION OF PATIENTS

\begin{tabular}{rccccc}
\hline Subject & $\begin{array}{c}\text { Age } \\
(y r)\end{array}$ & Sex & $\begin{array}{c}\text { Duration } \\
\text { of disease } \\
(y r)\end{array}$ & Stage & $\begin{array}{c}\text { Disability } \\
\text { before } \\
\text { L-dopa }\end{array}$ \\
\hline 1 & 62 & M & 7 & III & 18 \\
2 & 55 & M & 5 & IV & 26 \\
3 & 61 & F & 6 & II & 8 \\
4 & 68 & M & 9 & III & 11 \\
5 & 43 & F & 3 & III & 16 \\
6 & 47 & F & 4 & III & 14 \\
7 & 59 & F & 11 & IV & 28 \\
8 & 63 & M & 6 & III & 21 \\
9 & 71 & M & 9 & III & 18 \\
10 & 68 & M & 8 & II & 9 \\
11 & 65 & M & 6 & III & 13 \\
12 & 60 & F & 6 & III & 20 \\
\hline Average & $60 \cdot 2$ & & 6.7 & & 16.9 \\
\hline
\end{tabular}

an average age of $60 \cdot 2$ years. They had had Parkinsonism for an average of 6.7 years (range of 3 to 11 years). The patients were evaluated according to the criteria of Hoehn and Yahr (1967). Before L-dopa was started two patients were felt to be in stage II (bilateral involvement, minimal functional impairment) eight in stage III (impaired righting reflexes), and two in stage IV (severe involvement but able to walk and stand unassisted).

The disability of each patient was estimated according to the Northwestern Disability Scale (Canter et al., 1969). This is a scale which grades the patient's disability in six separate categories (walking, dressing, eating, feeding, hygiene, and speech) each graded numerically, and the sum of the six is taken as the total disability. In our study the patient's disability before L-dopa ranged from 8 to 28 with an average of 16.9 (Table 1 ).

All 12 patients had significant L-dopa induced dyskinesias which were felt to be the limiting factor in the response of each patient to L-dopa. This determination was made on the basis of one of the following criteria:

1. Dyskinesias were so distressing that we had had to decrease the daily L-dopa dosage with an observable decrease in its clinical efficacy (patients 1-7).

2. Dyskinesias had prevented our increasing the daily L-dopa dosage on at least two separate occasions when further increases were indicated because of limited efficacy (patients 8-12).

The patients were on L-dopa for an average of 13 months on a dosage ranging from 1.75 to $3.25 \mathrm{~g}$ /day with an average of $2.5 \mathrm{~g} /$ day. The improvement induced in each individual by L-dopa was calculated by subtracting the level of disability while on L-dopa from the pretreatment level. This number divided by the initial level of disability was taken as the degree of improvement (Klawans and Garvin, 1969).

Percent improvement

$$
=\frac{\text { Initial disability }- \text { disability on L-dopa }}{\text { Initial disability } \times 100}
$$

In the 12 patients studied here the disability after L-dopa averaged 11.3 with a range of 5 to 20 , representing an average improvement of $33 \%$ (Table $2)$. This contrasts with an average improvement of $57 \%$ in a group of 12 paired patients (matched for age, disability before L-dopa, and duration of disease) being treated at the same time, in whom dyskinesias had not limited L-dopa dosage. The average dosage of L-dopa in the 12 patients with severe dyskinesias was $2.5 \mathrm{~g}$ compared with $3.6 \mathrm{~g}$ in 12 patients without severe dyskinesias.

TABLE 2

RESPONSE TO L-DOPA AND HALOPERIDOL

\begin{tabular}{|c|c|c|c|c|}
\hline Subject & $\begin{array}{c}\text { Duration } \\
\text { on L-dopa } \\
\text { (months) }\end{array}$ & $\begin{array}{c}\text { Disability } \\
\text { on } \\
L \text {-dopa }\end{array}$ & $\begin{array}{c}\% \\
\text { Improve- } \\
\text { ment }\end{array}$ & $\begin{array}{c}\text { Daily } \\
\text { dose L-dopa } \\
(\mathrm{g})\end{array}$ \\
\hline 1 & 15 & 12 & 33 & 3.0 \\
\hline 2 & 11 & 18 & 30 & $3 \cdot 25$ \\
\hline 3 & 14 & 6 & 25 & 3.0 \\
\hline 4 & 10 & 6 & 45 & $2 \cdot 5$ \\
\hline 5 & 21 & 8 & 50 & $2 \cdot 5$ \\
\hline 6 & 15 & 6 & 57 & $3 \cdot 25$ \\
\hline 7 & 12 & 20 & 29 & $2 \cdot 25$ \\
\hline 8 & 8 & 18 & 14 & $1 \cdot 75$ \\
\hline 9 & 6 & 12 & 33 & $1 \cdot 50$ \\
\hline 10 & 20 & 5 & 44 & $2 \cdot 5$ \\
\hline 11 & 9 & 10 & 23 & $1 \cdot 75$ \\
\hline 12 & 14 & 14 & 30 & $3 \cdot 0$ \\
\hline Average & 13 & $11 \cdot 3$ & 33 & $2 \cdot 5$ \\
\hline
\end{tabular}

The patients were examined at weekly intervals and were given haloperidol in slowly increasing doses. All patients were begun on $0.5 \mathrm{mg}$ haloperidol once daily. The dosage was increased by $0.5 \mathrm{mg} /$ day at weekly intervals until the dyskinesias decreased or the disability increased. In eight patients the decrease in dyskinesias was paralleled by an increase in disability from Parkinsonism (patients 1-5 and 8-10). In these eight individuals subsequent increases in L-dopa dosage decreased the disability but increased the dyskinesias. In four patients (patients $6,7,11$, and 12) decreased dyskinesias were noted without $N$ increased disability. These patients were continued on the same dosage of haloperidol and within four weeks all manifested increased disability. Unsuccessful attempts were made in all these patients to lower 
TABLE 3

INFLUENCE OF HALOPERIDOL IN TWO GROUPS OF PATIENTS

Patients in whom any improvement in dyskinesias was accompanied by increased disability due to Parkinsonism

\begin{tabular}{lc}
\hline Subjects & $1,2,3,4,5,8,9,10$ \\
Average disability on L-dopa & $11 \cdot 4$ \\
Average L-dopa dosage & $2 \cdot 5 \mathrm{~g} /$ day \\
Average disability when dyskinesias improved & $16 \cdot 1$ \\
on haloperidol & 15.9 \\
Average disability before L-dopa & \\
\hline
\end{tabular}

Patients who initially had decreased dyskinesias without an initial decrease in disability due to Parkinsonism

\section{Subjects}

Average disability on L-dopa

Average L-dopa dosage

Average disability when dyskinesias noted to be improved

Average disability when haloperidol continued

Average disability before L-dopa

$6,7,11,12$

$12 \cdot 5$

$2 \cdot 5 \mathrm{~g} /$ day

$12 \cdot 1$

$17 \cdot 9$

$18 \cdot 7$

the dosage of haloperidol. The overall influence of haloperidol in these patients is summarized in Table 3. It should be noted that in the first group decrease in dyskinesia due to haloperidol resulted in a level of disability $(16 \cdot 1)$ which was greater than the average disability before L-dopa treatment. In the second group of patients continued use of haloperidol at a level which improved dyskinesias resulted in increased average disability (from 12.5 to 17.9) which approximated the average disability before L-dopa (18.7) in these four patients. No patients manifested significant worsening of Parkinsonism without some improvement in dyskinesias.

\section{DISCUSSION}

The theoretical basis for the use of haloperidol in the treatment of L-dopa induced dyskinesias is derived from a theory of the pathogenesis of choreatic movements first proposed by Klawans et al. (1971). These authors proposed that the abnormal choreiform movements in Huntington's chorea are due to an exaggerated or altered facilitatory effect of dopamine acting upon altered striatal neurones causing them to fire abnormally. They proposed an analogous mechanism for L-dopa induced dyskinesias.

This hypothesis was based upon a number of clinical and laboratory observations which suggested that two separate striatal neurone populations exist and that these two populations have different responses to dopamine and also have

different pathophysiological significance. This hypothesis relates choreiform movements to an altered response of small striatal dopamine facilitated neurones, while akinesia is viewed as involving altered (decreased) effect of dopamine upon the large striatal neurones (Klawans, 1973). Simply stated, this theory suggests the existence of two separate populations of dopamine receptor sites in the striatum. One of these is related to chorea, the other to akinesia (Parkinsonism). Different influence of dopamine on two postulated populations has possible therapeutic implications. Early observations had emphasized that dopamine had an inhibiting effect on striatal neurones (McLennan and York, 1967). More recent studies have shown that a significant percentage of dopamine responsive striatal neurones are actually facilitated by dopamine (York, 1970). It is of possible therapeutic significance that dopamine facilitated neurones appear to be more easily blocked by neuroleptic dopaminergic antagonism than dopamine inhibited neurones (York, 1970). This would suggest that low levels of neuroleptic agents such as haloperidol might block these receptors while sparing other receptors. If those receptors which are most easily blocked are related to chorea, neuroleptic dopamine antagonism might improve chorea without exacerbating Parkinsonism. Andén (1970), Carlsson (1970), and Klawans (1973) have all suggested that L-dopa induced chorea is due to an altered response of striatal neurones to dopamine. These authors all have suggested that denervation hypersensitivity underlies this altered response and Klawans (1973) has suggested that the mechanism is analogous to the pathophysiological mechanism of choreatic movements seen in Huntington's chorea. Since haloperidol frequently decreases the choreatic movements in Huntington's chorea without producing significant Parkinsonism in these patients (Birkmayer, 1969; Klawans, 1970), it was thought that this agent might improve L-dopa induced dyskinesias in patients with Parkinsonism without exacerbating their disability. Unfortunately, we were unable to do this successfully. In eight of our 12 patients initial improvement of dyskinesias was associated with increased disability, while in the other four patients continued haloperidol therapy at a level which decreased dyskinesia increased dis- 
ability within six weeks. These observations contrast with these of Postma (1972), who gave haloperidol to Parkinsonism patients with L-dopa induced dyskinesia and reported improvement in dyskinesias without worsening of Parkinsonism. Postma presented no details as to the duration of haloperidol induced improvement of dyskinesia without increased Parkinsonism. Our observation suggests that haloperidol given chronically is not of long-term value in decreasing L-dopa induced dyskinesia without increasing symptoms of Parkinsonism. The failure of this agent in chronic therapy is probably related to continued increase in central dopamine antagonism after chronic ingestion. Haloperidol induced Parkinsonism usually appears after several weeks of continued therapy (Man, 1973) and may reflect a similar phenomenon.

The observation that L-dopa induced dyskinesias can be decreased without worsening Parkinsonism for at least a brief period of time (patients 6, 7, 11, and 12) supports the hypothesis that separate striatal dopamine mechanisms are involved in chorea and Parkinsonism.

\section{REFERENCES}

Andén, N.-E. (1970). Pharmacological and anatomical implications of induced abnormal movements with L-dopa. In L-Dopa and Parkinsonism, pp. 132-143. Edited by A. Barbeau and F. H. McDowell. Davis: Philadelphia.

Barbeau, A. (1969). L-dopa therapy in Parkinson's disease. A critical review of nine years' experience. Canadian Medical Association Journal, 101, 59-68.

Barbeau, A., Mars, H., Gillo-Joffroy, L., and Arsenault, A. (1970). A proposed classification of dopa-induced dyskinesias. In $L$-Dopa and Parkinsonism, pp. 118-123. Edited by A. Barbeau and F. H. McDowell. Davis: Philadelphia.
Birkmayer, W. (1969). Der $\alpha$-Methyl-p-Tyrosin Effekt bei extrapyramidalen Erkrankungen. Wiener klinische Wochenschrift, 81, 10-12.

Canter, G. J., de la Torre, R., Mier, M. (1961). A method for evaluating disability in patients with Parkinson's disease. Journal of Nervous and Mental Disease, 133, 143-147.

Carlsson, A. (1970). Biochemical implications of dopainduced actions on the central nervous system, with particular reference to abnormal movements. In $L$-Dopa and Parkinsonism, pp. 205-213. Edited by A. Barbeau and F. H. McDowell. Davis: Philadelphia.

Cotzias, G. C., Papavasiliou, P. S., and Gellene, R. (1969) Modification of Parkinsonism-chronic treatment with L-dopa. New England Journal of Medicine, 280, 337-345.

Cotzias, G. C., Van Woert, M. H., and Schiffer, L. M. (1967). Aromatic amino acids and modification of Parkinsonism. New England Journal of Medicine, 276, 374-379.

Godwin-Austen, R. B., Tomlinson, E. B., Frears, C. C., and Kok, H. W. L. (1969). Effects of L-dopa in Parkinson's disease. Lancet, 2, 165-168.

Hoehn, M. M., and Yahr, M. D. (1967). Parkinsonism: onset, progression, and mortality. Neurology (Minneap.), 17, 427-442.

Jameson, H. D. (1970). Pyridoxine for levodopa-induced dystonia. Journal of the American Medical Association, 211, 1700.

Klawans, H. L., Jr. (1970). A pharmacologic analysis of Huntington's chorea. European Neurology, 4, 148-163.

Klawans, H. L., Jr. (1973). The Pharmacology of Extrc pyramidal Movement Disorders. Karger: Basel.

Klawans, H. L., Jr., and Garvin, J. S. (1969). Treatment o Parkinsonism with L-dopa. A study of 105 patient Diseases of the Nervous System, 30, 737-746.

Klawans, H. L., Jr., Ilahi, M. M., and Ringel, S. P. (1971 Toward an understanding of the pathophysiology Huntington's chorea. Confinia Neurologia, 33, 297-303.

Man, P. L. (1973). Long-term effects of haloperidol. Diseas of the Nervous System, 34, 113-118.

McLennan, H., and York, D. H. (1967). The action of dopamine on neurones of the caudate nucleus. Journal of Physiology, 189, 393-402.

Postma, J. U. (1972). Haloperidol in dopa-induced choreoathetosis. Psychiatria, Neurologia, Neurochirurgia, 75, 6971.

Yahr, M. D., Duvoisin, R. C., Schear, M. J., Barrett, R. E., and Hoehn, M. M. (1969). Treatment of parkinsonism with levodopa. Archives of Neurology, 21, 343-354.

York, D. H. (1970). Possible dopaminergic pathway from substantia nigra to putamen. Brain Research, 20, 233-249. 